\title{
The promoted dissolution of copper oxide nanoparticles by dissolved humic acid: Copper complexation over particle dispersion
}

\author{
Siqian Liu ${ }^{\text {a, b }}$, Yang Liu ${ }^{\text {a, b, * , Bo Pan }}{ }^{\text {a, b }}$, Ying He ${ }^{\text {a, b }}$, Bowen Li ${ }^{\text {a, b }}$, Dandan Zhou ${ }^{\text {a, b }}$, \\ Yinlong Xiao ${ }^{\mathrm{c}}$, Hao Qiu ${ }^{\mathrm{d}}$, Martina G. Vijver ${ }^{\mathrm{e}}$, Willie J.G.M. Peijnenburg ${ }^{\mathrm{e}, \mathrm{f}}$ \\ ${ }^{a}$ Faculty of Environmental Science and Engineering, Kunming University of Science and Technology, Kunming, 650500, China \\ b Yunnan Provincial Key Laboratory of Carbon Sequestration and Pollution Control in Soils, Kunming, 650500, China \\ ${ }^{c}$ College of Environmental Sciences, Sichuan Agricultural University, Wenjiang, 611130, China \\ d School of Environmental Science and Engineering, Shanghai Jiao Tong University, Shanghai, 200240, China \\ e Institute of Environmental Sciences (CML), Leiden University, Leiden, 2300, RA, the Netherlands \\ ${ }^{\mathrm{f}}$ National Institute of Public Health and the Environment (RIVM), Center for Safety of Substances and Products, Bilthoven, 3720, BA, the Netherlands
}

\section{H I G H L I G H T S}

- DHA promoted the dissolution of $\mathrm{CuO}$ NPs in a concentrationdependent fashion.

- Complexation, adsorptivity of CuO NPs decreased with increasing concentrations of DHA.

- Homo-conjugation promoted by $(-)$ charge-assisted $\mathrm{H}$-bond lead to DHA self-aggregation.

- DHA self-aggregation was responsible for reduced complexation, adsorption of CuO NPs.

- Driving force of CuO NPs dissolution was complexation instead of particle dispersion.
G R A P H I C A L A B S T R A C T

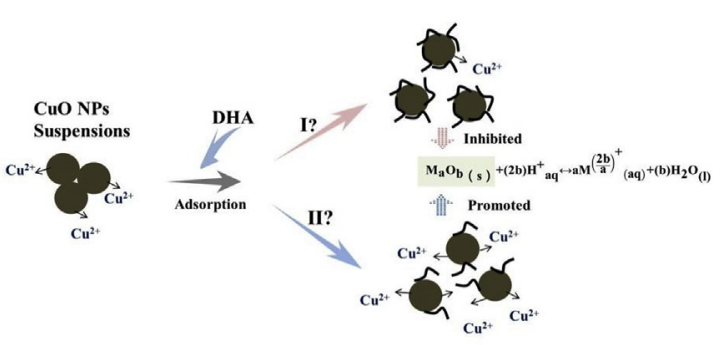

\begin{abstract}
A B S T R A C T
Humic substances are the dominant dissolved organic matter fraction in the aqueous phase of environmental media. They would inevitably react with chemicals released into the environment. The influence of dissolved humic acid (DHA) on the dissolution and dispersion of copper oxide nanoparticles (CuO NPs, $50 \mathrm{~nm}, 49.57 \mathrm{mg} \mathrm{L}^{-1}$ ) was therefore investigated in the present study. In addition to dispersing $\mathrm{CuO}$ NPs and reducing the size of the aggregates, the amount of released $\mathrm{Cu}$ from $\mathrm{CuO}$ NPs was found to increase over time with increasing concentrations of DHA, 96\% of which was present as organic complexes after $72 \mathrm{~h}$. At DHA concentrations exceeding $16.09 \mathrm{mg} \mathrm{C} \mathrm{L}^{-1}$, the complexation coefficients of DHA with $\mathrm{Cu}$ and the adsorptivity of CuO NPs to DHA were both reduced due to increased homo-conjugation of DHA as promoted by negative charge-assisted $\mathrm{H}$-bond. Although the adsorption capacity of DHA kept increasing up to $57.07 \mathrm{mg} \mathrm{C} \mathrm{L}^{-1}$, the hydrodynamic diameter and $\zeta$-potential were similar and the percentages of total released $\mathrm{Cu}$ continued to increase linearly to $4.92 \%$ at higher levels of DHA (30.13 $-57.07 \mathrm{mg} \mathrm{C} \mathrm{L}^{-1}$ ). Thereupon, DHA promoted the dissolution of CuO NPs in a concentration-dependent fashion. The driving force was complexation of $\mathrm{Cu}$ by DHA, rather than the balancing between the exposed and the covered surface area of the CuO NPs due to DHA adsorption. Our findings facilitate
\end{abstract}

\footnotetext{
* Corresponding author. Faculty of Environmental Science and Engineering, Kunming University of Science and Technology, Kunming, 650500, China.

E-mail addresses: minipig6@163.com, 20150095@kust.edu.cn (Y. Liu).
} 
understanding the underlying mechanisms on how DHA impacts the CuO NPs environmental behavior (or fate) as well as on their kinetics.

() 2019 Elsevier Ltd. All rights reserved.

\section{Introduction}

Copper oxide nanoparticles (CuO NPs) have integrated good physicochemical properties and are therefore widely applied in catalysts, semiconductor materials, and photo-voltaic materials (Khataee et al., 2016). The high use volume of CuO NPs inevitably induces their release into the environment during production, application or treatment (Zhao et al., 2013) and poses potential risks to environmental organisms (Park et al., 2014; Jiang et al., 2017; Gao et al., 2018) and to humans (Weichenthal et al., 2007). Some metal-based nanoparticles are not stable in aqueous media (Milne et al., 2017) and may dissolve and release metal ions according to the following equation (Wang et al., 2016):

$$
\mathrm{M}_{a} \mathrm{O}_{b(\mathrm{~s})}+(2 b) \mathrm{H}_{\mathrm{aq}}^{+} \leftrightarrow a \mathrm{M}^{\left(\frac{2 b}{a}\right)^{+}}(\mathrm{aq})+(b) \mathrm{H}_{2} \mathrm{O}_{(\mathrm{l})}
$$

$\mathrm{M}_{a} \mathrm{O}_{b}$ : metallic oxide nanoparticles; s: solid; aq: aqueous; 1 : liquid; $\mathrm{M}^{(2 b / a)+}$ : metal ions released from metallic oxide nanoparticles. The metal ions formed are in general more mobile (Conway et al., 2015) and more bioavailable to organisms (Jiang et al., 2017).

Humic substances such as humic acid (HA) are the dominant dissolved organic matter (DOM) fraction (Mostofa et al., 2013) which are commonly found in the aqueous phase of environmental media (Akaighe et al., 2011). Nanoparticles released in the environment may undergo various transformations inevitably together with HA (Aiken et al., 2011; Gunsolus et al., 2015). Recent studies already indicated that DOM as an active chemical component in the environment has significant influences on the dissolution of $\mathrm{ZnO}$ NPs (Jiang et al., 2015), adsorption of $\mathrm{SiO}_{2}$ NPs (Liang et al., 2011), desorption of $\mathrm{TiO}_{2}$ NPs (Mudunkotuwa and Grassian, 2010), transport of Cu NPs (Conway et al., 2015), and toxicity of $\mathrm{Cu}$ and $\mathrm{Pb}$ to Paracentrotus lividus larvae (Sánchezmarín et al., 2010). DOM, and especially HA, contains a large number of functional groups such as phenolic hydroxyl groups and carboxylic moieties (Jayalath et al., 2018). These functionalities allow HA to be an important source of dissolved adsorbent organic ligands (Liu and Gonzalez, 2000), e.g. they strongly bind with $\mathrm{Cu}^{2+}$ (Wang et al., 2015). Equation (1) is shifted to the right when the concentration of free metal ions is reduced by complexation. Meanwhile, $\mathrm{H}^{+}$can also be released from those functional groups through deprotonation which alters the chemical properties of the medium (Bian et al., 2011). Equation (1) will also shift to the right when the concentration of $\mathrm{H}^{+}$is increased (lower $\mathrm{pH}$ ). Up till now, however, the impact of adsorption of DOM on dissolution of metal-based NPs has mostly been neglected, especially with regard to the option of sorption of DOM altering the surface area of NPs exposed in suspensions and the subsequent impact on the equilibrium depicted in equation (1). As shown in equation (1), the equation will shift to the left when the concentration of metal oxide NPs drops and it will shift to the right when the concentration of NPs increases. Also, $\mathrm{CuO}$ NPs will have less opportunity to react with $\mathrm{H}^{+}$in solution when the surface area of CuO NPs exposed to the solution is reduced, which ultimately would inhibit the dissolution of $\mathrm{CuO}$ NPs. This may be the reason for the contradictive observations in literature of both inhibition (Gunsolus et al., 2015) and promotion
(Wang et al., 2015) of dissolution of metal-based NPs. Thus, the role of HA and its adsorption on NPs has to be clarified first to further understand the fate and behavior of CuO NPs in environmental media.

As stated in the research of Borm et al. (2006), the dissolution of solids is just a process in which constituent molecules migrate from the surface of the particles to the bulk solution through a diffusion layer. Due to the adsorption of HA, the thickness of the diffusion layer of CuO NPs on the particle surface would undoubtedly increase. As the amount of adsorption continues to increase before equilibrium, the migration of metal ions from the surface to the bulk solution would become more difficult which eventually leads to inhibited ion release. On the other hand, DOM will also reduce the hydrodynamic particle size of metal-based NPs suspended in the solution (Jiang et al., 2015). As the dispersion of CuO NPs is enhanced by DOM, their specific surface area may also be increased. This would increase the possibility of interaction between the surface of $\mathrm{CuO}$ NPs and $\mathrm{H}^{+}$in the solution (see formula (1)), and promote the ion release (Zook et al., 2012). The apparent CuO NPs dissolution thus results from the balancing between the exposed (increased dissolution) and the covered (decreased dissolution) surface area when the particles are dispersed by HA (hypothesis 1).

However, the effective surface area of metal-based NPs exposed in a suspension containing DOM cannot be quantified directly by existing experimental means. To check the correlation between dispersion and adsorption in the presence of HA and their contributions to the dissolution of CuO NPs, hypothesis 2 was raised. Hypothesis 2 assumes that the amount of HA adsorbed on CuO NPs increases with increasing HA concentrations until saturation, while it is hypothesized that the amount of dissolved CuO NPs would decrease with the increase of adsorption. In this study, we tested the hypotheses presented above by observing the dissolution and dispersion of $\mathrm{CuO}$ NPs under different levels of HA, whilst trying to figure out their relationships with HA adsorption on the particles.

\section{Materials and methods}

\subsection{Test compounds}

Uncoated CuO NPs (nano-spheres, nominal particle size $50 \mathrm{~nm}$, purity 99.5\%) were purchased from the Aladdin Reagent Company (Shanghai, China). $\mathrm{NaNO}_{3}$ (purity 99.99\%), used for keeping the ionic strength of the background solution at $0.1 \mathrm{M}$, was also purchased from the Aladdin Reagent Company (Shanghai, China). The background solution was composed of $\mathrm{NaNO}_{3}(0.1 \mathrm{M})$ and applied for preparing the dissolved humic acid (DHA) samples in different concentrations. $\mathrm{Cu}\left(\mathrm{NO}_{3}\right)_{2} 2.5 \mathrm{H}_{2} \mathrm{O}$ (purity $>99.8 \%$ ) for titration experiments was purchased from Alfa Aesar Company (Tianjin, China). HA was manually extracted from Dianchi Lake (N $24^{\circ} 48^{\prime} 19.22^{\prime \prime}$, E $102^{\circ} 39^{\prime} 52.16^{\prime \prime}$, Yunnan province, China) sediment using a traditional alkaline extraction method (Kang and Xing, 2005). The collected sediments samples were freeze-dried, ground, and sieved through a $2 \mathrm{~mm}$ sieve. Details of the preparation method of HA were presented in our previously published contribution (Pan et al., 2013). The fourth extraction (HA4) was used in this study. An amount of $0.5 \mathrm{~g}$ of HA4 was dissolved in $10 \mathrm{~mL}$ of $\mathrm{NaOH}$ solution $(0.5 \mathrm{M})$ overnight, diluted with $500 \mathrm{~mL}$ of 
ultrapure water, and filtered with a $0.45 \mu \mathrm{m}$ filter after adjusting the solution $\mathrm{pH}$ to 7 with $\mathrm{HNO}_{3}(0.1 \mathrm{M})$ to obtain the DHA stock solutions. The actual concentration of DHA in the stock solutions was determined by a total organic carbon analyzer (Vario TOC select, Elementar, Germany).

\subsection{Characterization of $\mathrm{CuO} N \mathrm{NS}$ and $H A$}

The primary morphology and particle size of CuO NPs prepared in the background solution and in the DHA solutions were characterized using a Tecnai $\mathrm{G}^{2}$ TF30 Transmission Electron Microscope (TEM, FEI Company, Netherland). The particle size of CuO NPs was determined using a Nano Measurer 1.2 (Fudan University, China). The distribution of hydrodynamic diameter, and the $\zeta$-potential of CuO NPs in the background solution and in the DHA solutions of different concentrations were measured by dynamic light scattering (DLS) on a Zeta PALS instrument (Brook Haven, USA).

The contents of $\mathrm{C}, \mathrm{H}, \mathrm{O}, \mathrm{N}, \mathrm{S}$ in the HA4 were analyzed by an elemental analyzer (Vario MICRO cube, Elementar, Germany). Fluorescence excitation-emission-matrix (EEM) spectrophotometry (LS-55, PerkinElmer, USA) was used to analyze the chemical composition or properties of DHA as a function of concentration before and after the exposure to CuO NPs. The spectrometer used a xenon excitation source, the scanning ranges were $200-800 \mathrm{~nm}$ for excitation and 200-800 $\mathrm{nm}$ for emission. The slits for both excitation and emission were $10 \mathrm{~nm}$ at a scanning speed of $600 \mathrm{~nm} \mathrm{~min}{ }^{-1}$.

\subsection{Experimental setup}

\subsubsection{Dissolution experiment}

It was reported that the concentration of dissolved organic carbon (DOC) in the river was around $5 \mathrm{mg} \mathrm{C} \mathrm{L}^{-1}, 40-80 \%$ of which was contributed by HA and fulvic acid (Leenheer, 1994). However, DOC concentrations vary a lot across different environmental media. For example, it reached a high level of $58 \mathrm{mg} \mathrm{L}^{-1}$ in the Mekong delta (Berg et al., 2007). According to the pre-experiment, DHA stock solutions were diluted to nominal concentrations of $0,5,10$, $25,50,75,100 \mathrm{mg} \mathrm{C} \mathrm{L}^{-1}$ using the background solution. The $\mathrm{pH}$ values of all treatments were adjusted to 7 using $\mathrm{NaOH}(0.1 \mathrm{M})$ to shield the role of varying $\mathrm{pH}$ values on $\mathrm{CuO}$ NPs dissolution. The real concentrations of DHA in the solution were then determined by TOC and used for further analysis. Five mg of CuO NPs were then added to $100 \mathrm{ml}$ of each of the DHA solution to reach a nominal concentration of $50 \mathrm{mg} \mathrm{L}^{-1}$. This concentration was set around median lethal concentrations of CuO NPs to some common organisms e.g. $45.7 \mathrm{mg} \mathrm{L}^{-1}$ for Chlorella pyrenoidosa (Zhao et al., 2016), $61.1 \mathrm{mg} \mathrm{L}^{-1}$ for Bacillus subtilis and $65.9 \mathrm{mg} \mathrm{L}^{-1}$ for Streptococcus aureus (Baek and An, 2011). The actual concentrations of the $\mathrm{CuO}$ NPs suspensions were analyzed using flame atomic absorption spectroscopy (FAAS, Hitachi, Japan). All suspensions were sonicated for 10 min (Tianjin Automatic Science Instrument Company, China) and placed with foil on a thermostatic shaker $\left(25^{\circ} \mathrm{C}\right)$ at $120 \mathrm{rpm}$ to mimic the water flow disturbance. The amount of free $\mathrm{Cu}^{2+}$ released from $\mathrm{CuO}$ NPs was measured using a $\mathrm{Cu}$-ion selective electrode (CUO1503, Van London-pHoenix, U.S.) from $1 \mathrm{~h}$ to $72 \mathrm{~h}$. All treatments were duplicated.

\subsubsection{Adsorption experiments}

Adsorption experiments were conducted to determine the amount of DHA adsorbed on the CuO NPs. DHA solutions were prepared at nominal concentrations of $5,10,25,50,75,100 \mathrm{mg} \mathrm{C}$ $\mathrm{L}^{-1}$ and placed in $100 \mathrm{~mL}$ reagent bottles. Different weights of $\mathrm{CuO}$ NPs were added to the reagent bottles to ensure the concentrations of $\mathrm{CuO}$ NPs at 0 or $50 \mathrm{mg} \mathrm{L}^{-1}$. All treatments were sealed with foil and incubated at $25^{\circ} \mathrm{C}$ on a rotatory shaker at $120 \mathrm{rpm}$ for $72 \mathrm{~h}$. The content of TOC in the supernatant was then measured after centrifugation at $3500 \mathrm{~g}$ for $10 \mathrm{~min}$. The difference of TOC in the solution with or without CuO NPs was used to quantify the amount of DHA adsorbed on the CuO NPs. All treatments were repeated three times.

\subsubsection{Chemical titration of surface reactive groups}

Due to the heterogeneous nature of DHA (Chen et al., 2015), the chemical composition of the DHA used in the present study was unknown. Chemical titration experiments were therefore conducted to determine the contents of two typical functional groups at different concentrations of DHA, namely carboxyl and phenolic hydroxyl functional groups which are commonly considered to be important binding ligands of $\mathrm{Cu}^{2+}$ (Nierop et al., 2002; Jiang et al., 2015; Wang et al., 2015). DHA solutions were prepared in concentrations of $5,10,25,50,75,100 \mathrm{mg} \mathrm{C} \mathrm{L}^{-1}$ and placed in $100 \mathrm{~mL}$ reagent bottles. The $\mathrm{pH}$ values of the DHA solutions were adjusted to be 3 using $\mathrm{HNO}_{3}(0.1 \mathrm{M})$. Nitrogen was introduced into the solution to prevent the effects of carbon dioxide on titration (Ma et al., 2001). The DHA solutions were then titrated with $\mathrm{NaOH}(0.1 \mathrm{M})$ with the $\mathrm{pH}$ value as indicator. The $\mathrm{pH}$ values of the stable solution were determined and recorded every after the addition of $20 \mu \mathrm{L}$ of $\mathrm{NaOH}$ until 8 or 10 . The content of carboxyl functional groups was determined by the amount of $\mathrm{NaOH}$ consumed from $\mathrm{pH}=3$ to 8 . The content of phenolic hydroxyl functional groups was twice the amount of $\mathrm{NaOH}$ consumed from $\mathrm{pH}=8$ to 10 (Ma et al., 2001).

\subsubsection{Quantification of complexation in the presence of DHA}

The total amount of $\mathrm{Cu}^{2+}$ that was released from $\mathrm{CuO}$ NPs in the presence of DHA should be the sum of the free $\mathrm{Cu}^{2+}$ activities and the concentrations of complexed ions (organic and inorganic complexes) because dissolved organic matter can strongly bind with $\mathrm{Cu}^{2+}$ (Jiang et al., 2017). The total amount of complexed $\mathrm{Cu}$ was calculated through the binding curves at different concentrations of DHA $(\mathrm{pH} \approx 7)$ which were generated by the complex titration method. The amount of inorganic complexes was assessed by the Windermere Humic Aqueous Model 7.0.1 (Centre for Ecology \& Hydrology, Wallingford, UK) speciation model based on the amount of free $\mathrm{Cu}^{2+}$ as determined by the $\mathrm{Cu}$-ion selective electrode. The amount of organic complexes was equal to the difference between the total amount of complexed $\mathrm{Cu}$ and the amount of inorganic complexes. The detailed description of the complex titration method can be found in our previous study of Zhao et al. (2017).

\subsubsection{Data analysis}

The binding curves, i.e. the relationships between the free $\mathrm{Cu}^{2+}$ activities and the amount of complexed $\mathrm{Cu}$ were obtained using the Formation Function model (Benedetti et al., 1995) which is presented in equation (2) and which was run by the OriginPro 8 software (Origin Lab, USA):

$M L=\frac{K * L * M_{f}}{1+K * M_{f}}$

$M L$ : the concentration of complexed $\mathrm{Cu}, \mathrm{M} ; K$ : the complexation stability constant; $L$ : the concentration of ligand, $M ; M_{f}$ : the free $\mathrm{Cu}^{2+}$ activity, M. With the known $K$ and $L$ values, the concentrations of complexed $\mathrm{Cu}$ in the system with $\mathrm{CuO}$ NPs can then be calculated using equation (2).

The curves of released $\mathrm{Cu}^{2+}$ concentration versus time were fitted using a modified pseudo second-order model (PSOM) (Pan et al., 2012) in OriginPro 8: 
$y(t)=y($ final $)\left(k \frac{t}{(1+k * t)}\right)$

$y(t)$ : the released $\mathrm{Cu}^{2+}$ concentrations, $\mu \mathrm{M} ; y$ (final): the released $\mathrm{Cu}^{2+}$ concentrations at $72 \mathrm{~h}, \mu \mathrm{M} ; k$ : the rate constant of $\mathrm{Cu}$ release, $\mathrm{h}^{-1} ; t$ : the exposure time, $\mathrm{h}$.

The titration curves of surface functional groups at various DHA levels, i.e. the relationships between the consumption of $\mathrm{NaOH}$ and $\mathrm{pH}$ were also obtained using the logistic model in OriginPro 8. It was theoretically assumed that the contents of functional groups in DHA would be increased with increasing concentrations of DHA. To determine whether there were interactions promoted by negative charge-assisted H-bond formation between DHA molecules, which would result in a decreased surface reactive groups with increasing DHA concentrations, formula (4) (Zhao et al., 2018) was used to determine the homo-conjugation. The $\mathrm{p} K_{\mathrm{a}}$ values at different DHA concentrations were approximately equal to the $\mathrm{pH}$ values of the half neutralization points (Zafar et al., 2014):

$$
\begin{aligned}
\log C_{\mathbf{C u}-\mathbf{L}}= & \log K_{\mathbf{c}} \\
& +\log \left(\frac{\left.-\left(1+\frac{\left[\mathrm{H}^{+}\right]}{K_{\mathbf{a}}}\right)+\sqrt{\left(\left(1+\frac{\left[\mathrm{H}^{+}\right]}{K_{\mathbf{a}}}\right)^{\mathbf{2}}+4\left[\mathrm{H}^{+}\right] K_{\mathbf{L H L}} C_{\mathbf{T}}\right.}\right)}{2\left[\mathrm{H}^{+}\right] K_{\mathbf{L H L}}}\right) \\
& +\log C_{\mathbf{C u}}
\end{aligned}
$$

$C_{\mathrm{Cu}-\mathrm{L}}$ : the concentration of $\mathrm{Cu}^{2+}$ bound to DHA, M; $K_{\mathrm{c}}$ : the complexation stability constant, $\left(\mathrm{g} \mathrm{L}^{-1}\right)^{-1} ; C_{\mathrm{Cu}}$ : the free $\mathrm{Cu}^{2+}$ activity, $\mathrm{M} ;\left[\mathrm{H}^{+}\right]$: the concentration of $\mathrm{H}^{+}=10^{-7} \mathrm{M}(\mathrm{pH}=7) ; K_{\mathrm{a}}$ : Acid equilibrium constant, $\mathrm{M}$, which was obtained by the transformation of the $\mathrm{p} K_{\mathrm{a}}$ values in Fig. S4; $C_{\mathrm{T}}$ : the concentration of DHA, $\mathrm{g} \mathrm{L}^{-1}$; $K_{\mathrm{LHL}}$ : homo-conjugation constant between HA molecules, $\left(\mathrm{g} \mathrm{L}^{-1}\right)^{-2}$.

\section{Results and discussion}

\subsection{Characterization of $\mathrm{CuO}$ NPs and DHA}

The $\mathrm{C}, \mathrm{H}, \mathrm{O}, \mathrm{N}$, and $\mathrm{S}$ contents of the HA4 were analyzed to be $53.6 \%, 4.8 \%, 32.5 \%, 3.2 \%$, and $1 \%$ respectively. The TEM pictures showed that the $\mathrm{CuO}$ NPs were spherical agglomerates in the background solution and their average size was approximately $93 \pm 5 \mathrm{~nm}\left(n=10\right.$, Fig. 1. (a)). When $4.37 \mathrm{mg} \mathrm{C} \mathrm{L}^{-1}$ of DHA was added in the solution, the size of CuO NPs was reduced to $77 \pm 3 \mathrm{~nm}$ ( $n=10$, Fig. 1. (b)); the size of CuO NPs aggregates dropped to $56 \pm 2 \mathrm{~nm}(n=10$, Fig. 1. (c)) when DHA concentration in the solution reached $16.09 \mathrm{mg} \mathrm{C} \mathrm{L}^{-1}$. These TEM images revealed that the morphology of the $\mathrm{CuO}$ NPs agglomerates was not changed significantly by the added DHA, while their size was reduced upon increasing concentrations of DHA. This may indicate an improved dispersion of $\mathrm{CuO}$ NPs in the suspensions with DHA. Further demonstration should be based on the results of DLS (see section 3.4).

\subsection{Quantification of the complexation between $\mathrm{Cu}^{2+}$ and $\mathrm{DHA}$}

According to the $\mathrm{Cu}$ speciation in the solutions, as estimated by the Windermere Humic Aqueous Model 7.0.1 (see Fig. S1), the amount of organically complexed $\mathrm{Cu}$ was $12-7000$ times higher than the amount of inorganic complexed $\mathrm{Cu}$. Thus, the discussion regarding $\mathrm{Cu}$ complexation will be mostly focused on the organic complexed $\mathrm{Cu}$ in the present study.

Based on the binding curves generated by the Formation Function model (see Fig. S2), the amount of $\mathrm{Cu}^{2+}$ released from $\mathrm{CuO}$ NPs bound with DHA molecules can be estimated on the basis of the measured free $\mathrm{Cu}^{2+}$ activities. It was generally found that the higher the DHA concentrations were, the more complexed $\mathrm{Cu}$ was produced, which implied that more binding sites were provided by the increased amount of DHA added in the solution. This observation is consistent with previous findings (Jiang et al., 2017). Moreover, the complexation stability constant (log $K$ ) first sharply increased as the concentration of DHA increased, and then did not change significantly when the concentration of DHA reached $30.13 \mathrm{mg} \mathrm{C} \mathrm{L}^{-1}$. This indicated that the binding affinity of $\mathrm{Cu}^{2+}$ was proportional to the DHA concentrations at low levels of DHA (4.37-16.09 $\left.\mathrm{mg} \mathrm{C} \mathrm{L}^{-1}\right)$, whereas it became constant in the case of high DHA concentrations (30.13-57.07 $\mathrm{mg} \mathrm{C} \mathrm{L}^{-1}$ ). Some researchers suggested that this may be a consequence of self-aggregation (Leenheer and Croue, 2003) of DHA or of strong intermolecular interactions between DHA molecules at high DHA levels. To verify whether the binding sites of DHA or its intermolecular force change when varying the concentration of DHA, chemical titration experiments were conducted and the homo-conjugation between DHA molecules was calculated, the results of which were shown and discussed in the following sections.

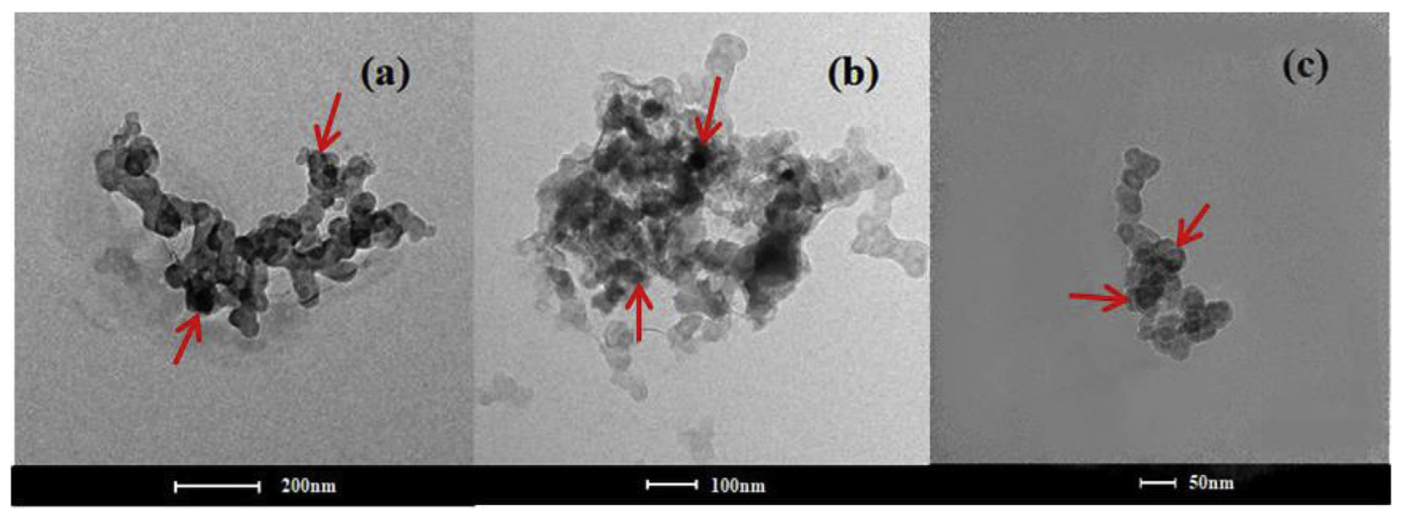

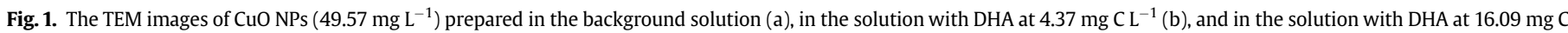

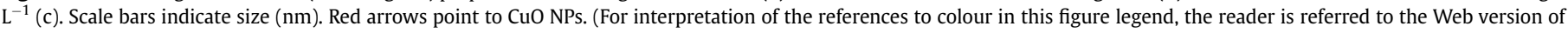
this article.) 


\subsection{Dissolution of CuO NPs in the presence of DHA}

Dissolution of NPs is one of the most important processes determining the environmental behavior, fate and risks of NPs in the long term. Also in view of its close relationship with aggregation, dispersion, transport and uptake, it is essential that dissolution seriously considered and comprehensively understood. As shown in Fig. 2, the kinetics of total $\mathrm{Cu}^{2+}$ release from CuO NPs, the concentration of complexed $\mathrm{Cu}$, and the free $\mathrm{Cu}^{2+}$ concentration at different concentrations of DHA can be reasonably well described by the modified pseudo-second-order model (equation (3)). Generally, the amount of total $\mathrm{Cu}^{2+}$ released from $\mathrm{CuO}$ NPs increased over time, and was promoted upon increased DHA addition. This was consistent with our previous study for tannic acid (Zhao et al., 2017), in which it was found that the dissolution kinetics of $\mathrm{CuO}$ NPs were strongly influenced by the concentration of dissolved organic matter. Most notably, at the DHA concentration of $57.07 \mathrm{mg} \mathrm{C} \mathrm{L}^{-1}$, the total amount of $\mathrm{Cu}^{2+}$ released from CuO NPs
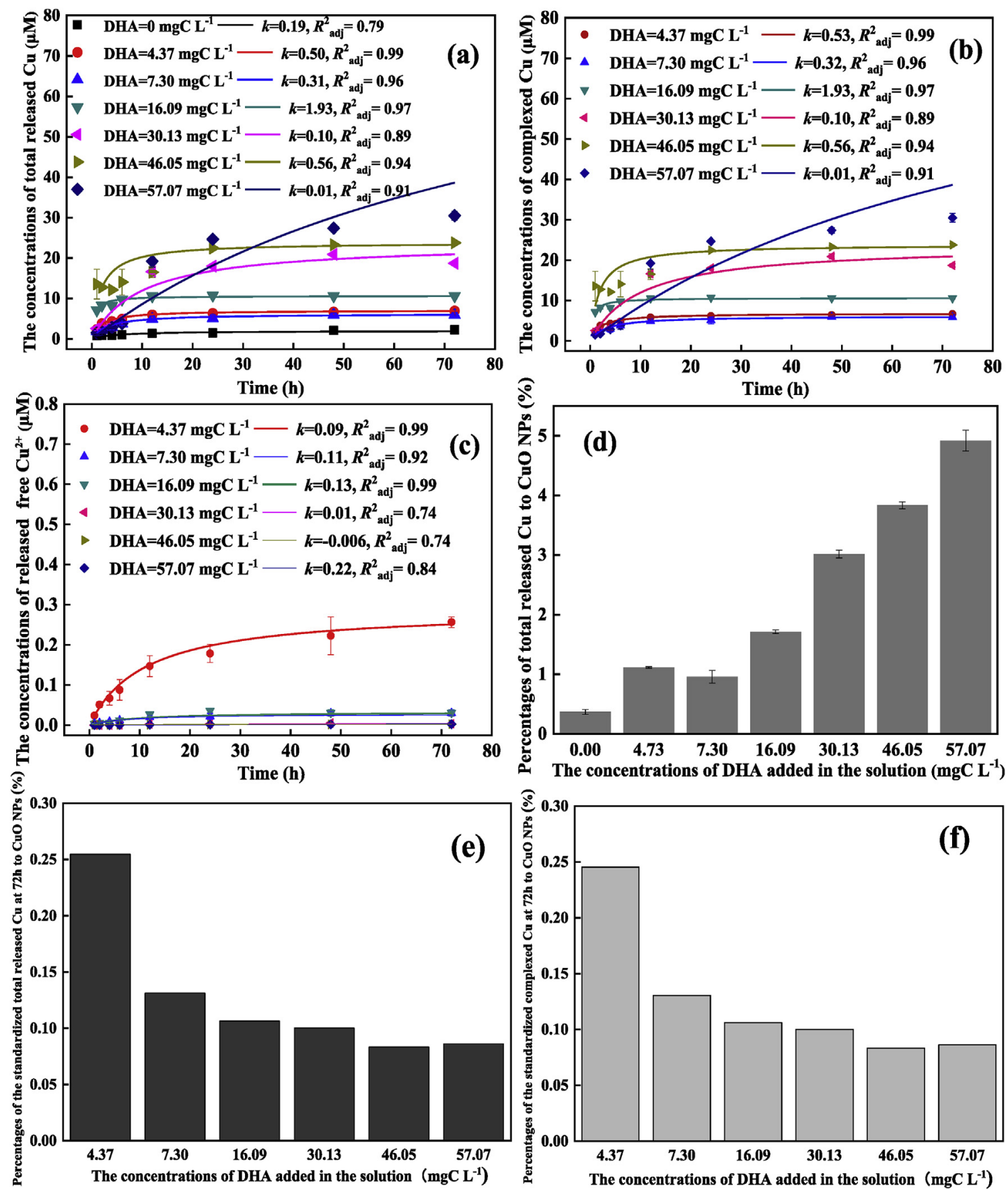

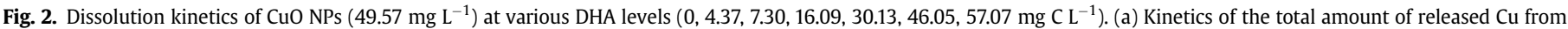

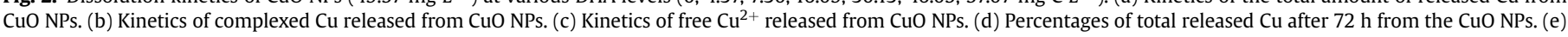

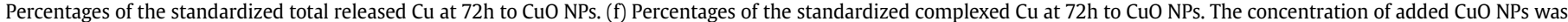

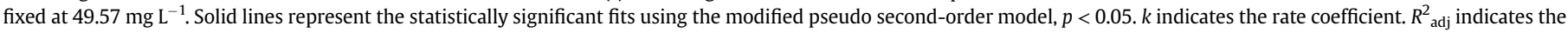
adjusted determination coefficient. 
during $72 \mathrm{~h}$ was more than 13 times higher than the release of $\mathrm{Cu}^{2+}$ in the absence of DHA. The dissolution rate constant reached a maximum $\left(k=1.93 \mathrm{~h}^{-1}\right)$ at DHA $=16.09 \mathrm{mg} \mathrm{C} \mathrm{L}^{-1}$, which implied that the dissolution equilibrium can be achieved faster at this concentration (Jiang et al., 2015). However, the extent of increase in dissolution rate of $\mathrm{CuO}$ NPs was not in close relationship with the concentrations of DHA. Different factors may contribute to this phenomenon, such as surface coating and aggregation state (David et al., 2012; Jiang et al., 2015). These variables can be spatially and temporally highly heterogeneous (Vijver et al., 2018). Thus, the dynamics of aggregation/agglomeration of NPs and adsorption of DHA are further evaluated in the following sections.

Moreover, the amount of complexed $\mathrm{Cu}$ also varied with time and its trend was very similar to that of the total amount of released $\mathrm{Cu}$. On the contrary, the concentrations of released free $\mathrm{Cu}^{2+}$ in the solution decreased with the increasing DHA concentrations and reached a maximum at the lowest concentration of DHA $(4.37 \mathrm{mg} \mathrm{C}$ $\mathrm{L}^{-1}$ ). Comparing Fig. 2(a), (b) and (c), the amount of free $\mathrm{Cu}^{2+}$ in solution at $72 \mathrm{~h}$ was found to only account for less than $4 \%$ of the total amount of $\mathrm{Cu}^{2+}$ in the presence of DHA. Such a large proportion of complexed $\mathrm{Cu}$ indicated that the released $\mathrm{Cu}^{2+}$ from $\mathrm{CuO}$ NPs can quickly and strongly bind with DHA molecules in the suspension. Plaza et al. (2006) proposed that some structures in HA molecules such as two adjacent aromatic carboxyl groups (i.e. phthalic acid-like binding site) and an aromatic carboxyl group and adjacent phenolic hydroxyl group (i.e. salicylic acid-like binding site) can form stable bidentate complexes with metal ions. The structure and configuration of functional groups in DHA molecules can then be altered due to complexation (Yamashita and Jaffé, 2008), thus leading to the observed fluorescence intensity of DHA decreased by addition of CuO NPs (see Fig. S3). As the DHA concentration increased, the numbers of carboxyl groups and phenolic hydroxyl groups in suspension were generally detected to increase (see Table 1). More abundant functional groups provide more binding sites for $\mathrm{Cu}^{2+}$ (Wang et al., 2015) which resulted in an increase of the amount of $\mathrm{Cu}^{2+}$-DHA complexes with increasing concentrations of DHA (see Fig. 2 (b)). However, after carbon standardization, the content of carboxyl and phenolic hydroxyl groups was not positively linearly or became negatively correlated with the increased DHA concentrations. For instance, the concentration of phenolic hydroxyl groups was reduced to $5.74 \mathrm{mmol} \mathrm{g}^{-1}$ $\mathrm{C}$ at the DHA concentration as high as $57.07 \mathrm{mg} \mathrm{C} \mathrm{L}^{-1}$. This was less than $33 \%$ of the concentration of phenolic hydroxyl groups at the lowest DHA concentration of $4.37 \mathrm{mg} \mathrm{C} \mathrm{L}^{-1}$. This finding may be indicative of DHA self-aggregating that occurred due to the reduced intermolecular space for movements (Ghosh and Pal, 2007; Pan et al., 2008), thus resulting in the reduction of binding sites (i.e. carboxyl and phenolic hydroxyl groups) per unit mass of DHA molecules. According to equation (1), the equilibrium moves to the right when the amount of free metal ions is reduced, which increases the release of $\mathrm{Cu}^{2+}$ from the CuO NPs. Complexation of released $\mathrm{Cu}$ by DHA shifted the equilibrium, which results in enhanced dissolution of $\mathrm{CuO}$ NPs upon increasing DHA concentrations.
In addition, the percentages of total released $\mathrm{Cu}^{2+}$ were significantly increased upon increased addition of DHA (see Fig. 2(d)). This indicates that the solubility of $\mathrm{CuO}$ NPs is much larger in environmental media rich in DOM which was consistent with previous studies for TA (Zhao et al., 2017) and for humic substances (Wang et al., 2015). Interestingly, after removing the concentration effect, the standardized percentages of total released $\mathrm{Cu}$ or complexed $\mathrm{Cu}$ at $72 \mathrm{~h}$ were reduced upon increased addition of DHA (see Fig. 2 (e) and (f)). Especially at higher DHA concentrations ( > $\left.16.09 \mathrm{mg} \mathrm{C} \mathrm{L}^{-1}\right)$, the percentages of standardized total released $\mathrm{Cu}$ or complexed $\mathrm{Cu}$ from the $\mathrm{CuO}$ NPs were all below $0.1 \%$. This was just the same as the trend for complexation stability constants after carbon standardization (DHA concentrations from 4.37 to $57.07 \mathrm{mg} \mathrm{C} \mathrm{L} \mathrm{L}^{-1}, \log K=0.28>0.24>0.17>0.09 \approx 0.06 \approx 0.05$, Fig. S2). Excluding the concentration variable, the increase of DHA molecules per unit mass seemed to reduce its ability to bind with $\mathrm{Cu}$. These results not only verified the close relationship between $\mathrm{CuO}$ NPs dissolution and complexation, but also raised the questions: Why was the complexation ability of DHA with $\mathrm{Cu}$ reduced upon increasing concentrations of DHA? Is this related to selfaggregation? Will the adsorption of DHA on CuO NPs be influenced as well? All of these issues will be discussed in the following sections.

\subsection{The adsorption of DHA on CUO NPs and its effect on the dispersion of $\mathrm{CuO}$ NPS}

The adsorption of natural organic matter can disperse NPs and inhibit particle aggregation (Pan et al., 2013), which in turn influences the dissolution of NPs. The dispersion state of CuO NPs (as indicated by the hydrodynamic diameter and the $\zeta$-potential) was therefore assessed and DHA adsorption experiments were conducted to study the underlying mechanisms at similar aquatic chemical composition as used in the dissolution experiments. In the absence of DHA, CuO NPs usually exist as dispersed aggregates, the hydrodynamic diameter and the $\zeta$-potential of which reached $752 \pm 49 \mathrm{~nm}$ and $-4.5 \pm 2.3 \mathrm{mV}$ respectively as shown in Fig. 3. This may arise from the Brownian motion, the attractive van der Waals forces and hydrogen bonding of particles in aqueous solution (Ghosh and Pal, 2007). When DHA was added, the hydrodynamic diameter and the $\zeta$-potential of CuO NPs in the background solution significantly decreased to $583 \pm 41 \mathrm{~nm}$ and $-21.5 \pm 0.9 \mathrm{mV}$. Nevertheless, the reduced hydrodynamic diameter and the $\zeta$-potential were not negatively linearly correlated with the increasing DHA concentrations. When the DHA concentration was $>16.09 \mathrm{mg} \mathrm{C} \mathrm{L}^{-1}$, this downward trend became much slower. This indicated that DHA can greatly suppress the aggregation of $\mathrm{CuO}$ NPs, and it was effective in stabilizing the CuO NPs, while these effects were also concentration-specific.

As shown in Fig. 3 (a), the amount of DHA adsorption on CuO NPs kept increasing with increasing concentrations of DHA. To further validate the relevance of the DHA adsorption for dispersion of CuO NPs, the correlation was analyzed and shown in Fig. S5. The amount of DHA adsorbed on the CuO NPs was negatively correlated

Table 1

Contents of carboxyl groups and phenolic hydroxyl groups at various DHA levels tested by chemical titration method.

\begin{tabular}{|c|c|c|c|c|c|c|c|}
\hline \multicolumn{2}{|c|}{ Contents of surface functional groups } & \multicolumn{6}{|c|}{ The concentrations of DHA $\left(\mathrm{mg} \mathrm{C} \mathrm{L}^{-1}\right)$} \\
\hline & & 4.37 & 7.30 & 16.09 & 30.13 & 46.05 & 57.07 \\
\hline \multirow[t]{2}{*}{ Carboxyl groups } & $(\mathrm{mmol})$ & 0.0056 & 0.0174 & 0.0224 & 0.0524 & 0.0720 & 0.0813 \\
\hline & $\left(\mathrm{mmol} \mathrm{g}^{-1} \mathrm{C}\right)$ & 11.20 & 17.40 & 8.96 & 10.48 & 9.60 & 8.13 \\
\hline \multirow[t]{2}{*}{ Phenolic hydroxyl groups } & $(\mathrm{mmol})$ & 0.0088 & 0.0152 & 0.0252 & 0.0452 & 0.0660 & 0.0574 \\
\hline & $\left(\mathrm{mmol} \mathrm{g}^{-1} \mathrm{C}\right)$ & 17.60 & 15.20 & 10.08 & 9.04 & 8.80 & 5.74 \\
\hline
\end{tabular}



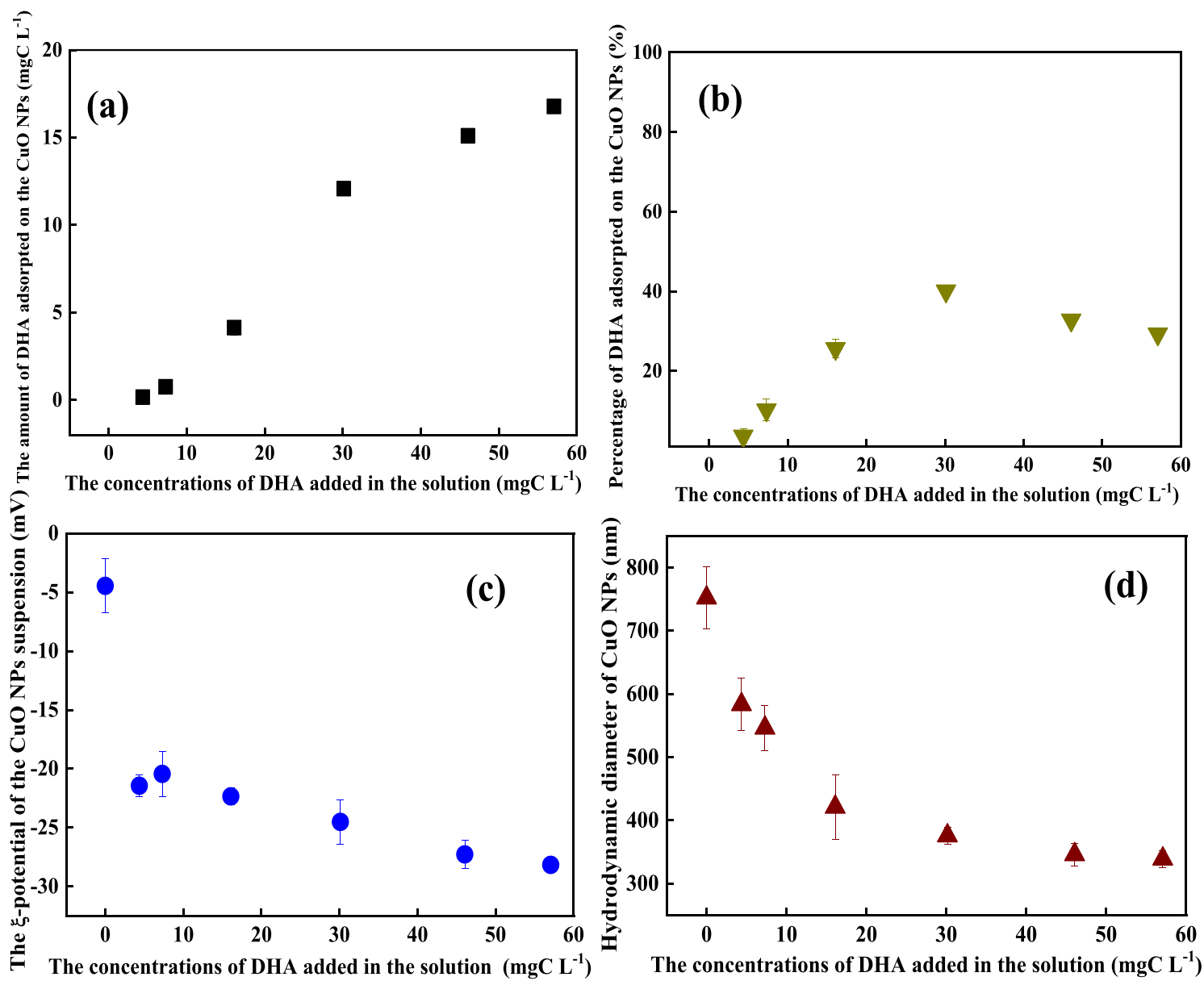

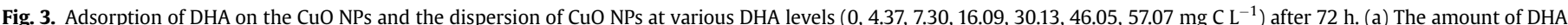

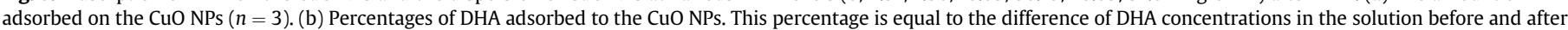

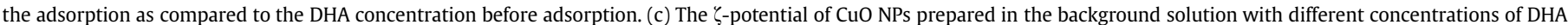

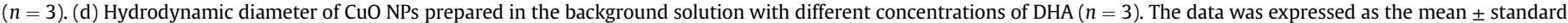
error of the mean.

with the hydrodynamic diameter and the $\zeta$-potential of CuO NPs prepared in the background solution at different levels of DHA. These results confirm that the adsorption of DHA on the surface of $\mathrm{CuO}$ NPs is involved in the decreased aggregation and increased dispersion of CuO NPs (Peng et al., 2017). Because the CuO NPs and DHA molecules were all negatively charged in the present study, they may combine with each other through ionic bridging (such as via $\mathrm{Na}^{+}$(Liang et al., 2011) in the solution) or ligand exchange (such as carboxyl groups or hydroxyl groups (Wang et al., 2016)). The adsorption of negatively charged DHA molecules will increase the charge density and the electrophoretic mobility (Jekel, 1986) of suspended CuO NPs with negatively charged surface groups. This may then enlarge the electrostatic repulsion between particles in the suspension and enhance dispersion of CuO NPs in the solution.

Coincidentally, the percentage of DHA adsorbed on the CuO NPs was also observed to increase sharply when DHA $\leq 30.13 \mathrm{mg} \mathrm{C} \mathrm{L}^{-1}$, whereas this percentage became steady or was even slightly reduced when DHA $>16.09 \mathrm{mg} \mathrm{C} \mathrm{L}{ }^{-1}$ (Fig. 3(b)). These results showed that unlike the adsorption capacity which kept increasing with the increase of concentration, the increase of adsorptivity of CuO NPs appeared to enter a phase of stagnation when DHA $>16.09 \mathrm{mg} \mathrm{C} \mathrm{L}^{-1}$. This explains why the hydrodynamic diameter and the $\zeta$-potential of $\mathrm{CuO}$ NPs in solution tended to be stable at higher concentrations of DHA. At higher levels of DHA ( $>16.09 \mathrm{mg} \mathrm{C}$ $\mathrm{L}^{-1}$ ), the adsorption of DHA on CuO NPs would be influenced. This leads to limitation of the effects of DHA on stabilizing CuO NPs in aqueous media.

An additional question that popped up was whether the selfaggregation of DHA molecules at higher concentrations played a key role in inhibiting solubility of CuO NPs, complexation ability between $\mathrm{Cu}$ and DHA and adsorptivity of CuO NPs, and what caused DHA molecules to self-aggregate.

\subsection{Correlation between dissolution and dispersion of CuO NPs}

In our system, DHA molecules were negatively charged. In principle, DHA molecules can disperse well owing to electrostatic repulsion (Philippe and Schaumann, 2014). However, the phenomena observed in the experiments were opposite, and even selfaggregation occurred among DHA molecules. This raises the question of what caused the unusually strong interactions between functional groups of molecules with the same charge? Some investigators suggested that relatively strong charge-assisted $\mathrm{H}$-bond formation (Mahmudov et al., 2017) as compared with the ordinary $\mathrm{H}$-bond formation may be the explanation. To unravel the questions raised in the above sections, the DHA homo-conjugation at different DHA concentrations was estimated using formula (4) and shown in Table 2 . The $\log K_{\mathrm{LHL}}$ values $\left(>16.09 \mathrm{mg} \mathrm{C} \mathrm{L}^{-1}\right.$ ) were found to be larger than that at low levels of DHA $\left(\leq 16.09 \mathrm{mg} \mathrm{C} \mathrm{L}^{-1}\right)$, which just indicated an increased negative charge-assisted $\mathrm{H}$-bond that 
Table 2

The estimated DHA homo-conjugation $\left(K_{\mathrm{LHL}}\right)$ at various DHA levels using formula (4).

\begin{tabular}{lllllll}
\hline Dissociation constants of DHA & \multicolumn{6}{c}{ The concentrations of DHA $\left(\mathrm{mg} \mathrm{C} \mathrm{L}^{-1}\right)$} \\
\cline { 2 - 7 } & 4.37 & 7.30 & 16.09 & 30.13 & 46.05 & 57.07 \\
\hline $\log K_{\mathrm{LHL}}\left(\mathrm{g} \mathrm{L}^{-1}\right)^{-2}$ & 7.50 & 7.50 & 7.50 & 7.57 & 7.57 & 7.57 \\
\hline
\end{tabular}

Note: dissociation constant values $\left(\mathrm{p} K_{\mathrm{a}}\right)$ of DHA were calculated from the titration curves of surface functional groups at various DHA levels in the present study (see Fig. S4); - indicates not determined in the present study.

was formed among DHA molecules at higher dose levels. Increased negative charge-assisted $\mathrm{H}$-bond formation may enhance the intermolecular forces among DHA molecules (Gilli and Gilli, 2000), thus leading to the decreased content of organic binding sites per unit mass of DHA such as carboxyl and phenolic hydroxyl groups (Hernández et al., 2006). Homo-conjugation of DHA promoted by the negative charge-assisted $\mathrm{H}$-bond can then compete with $\mathrm{Cu}$ for binding with DHA (Zhao et al., 2018). This allowed us to observe the reduced complexation ability $(\log K)$ of DHA with $\mathrm{Cu}$ and the decreased solubility of CuO NPs after carbon standardization. Similarly, the decrease of active sites of surface functional groups may also lead to the weakening of ligand exchange (Yang et al., 2009), which reduced the adsorptivity of CuO NPs to DHA and impacted the dispersion of particles in suspension especially when

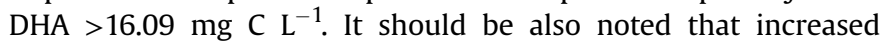
intermolecular forces among DHA molecules may be the result of various covalent and non-covalent bonds, e.g. $\pi-\pi$ stacking interactions, hydrogen bond, and van der Waals force (Philippe and Schaumann, 2014). In the present study, it was only concluded that self-aggregation or homo-conjugation of DHA molecules has a greater relationship with the negative charge-assisted $\mathrm{H}$-bond, but other factors cannot be excluded yet.

When focusing on the high DHA concentrations, many problems like the relationship between dissolution and dispersion can be readily solved. As shown in Fig. 3(c) and (d) when DHA $>16.09 \mathrm{mg} \mathrm{C}$ $\mathrm{L}^{-1}$, variations of the hydrodynamic diameter and the $\zeta$-potential of CuO NPs in the solution did not exceed $10 \%$. This indicated that DHA has a small influence on dispersing CuO NPs and increasing their surface area that was available for dissolution, while the adsorption capacity was still increasing. If hypothesis 1 was correct, the apparent $\mathrm{CuO}$ NPs dissolution would be decreased because of the increasing surface area covered by DHA. In reality, however, dissolution continued, and the percentages of total released $\mathrm{Cu}$ to $\mathrm{CuO}$ NPs still showed a trend of linear increase. These results illustrated that hypothesis 1 could be rejected. Hypothesis 2 was also rejected that the surface of CuO NPs cannot be completely occupied by DHA at the present concentrations (Fig. 3(a)) possibly because of the homo-conjugation of DHA promoted by the negative charge-assisted $\mathrm{H}$-bond. Thus, it was maintained in the present study that the promoted dissolution of CuO NPs by DHA should be attributed to copper complexation (which is consistent with previous studies (Jiang et al., 2015)) rather than by enhanced particle dispersion. It is also noted that the present study focused on exploring the correlation between the extend of CuO NPs dissolution and the particle surface area exposed to the solution. This is only a beginning to further understand how natural organic matter impacts the behavior of CuO NPs. Further efforts are needed to extrapolate our findings across different environmentally realistic conditions.

\section{Conclusions}

Although there are various studies related to assessing the environmental behavior of CuO NPs in the presence of DOM, the effective surface area of CuO NPs exposed to the solution with DOM still cannot be directly quantified by existing experimental means. We observed that the amount of $\mathrm{Cu}$ released from $\mathrm{CuO}$ NPs kept increasing with the increase of the adsorption capacity, and the stability of CuO NPs in the suspension was enhanced when DHA was introduced into the system. Complexed $\mathrm{Cu}$ was found to account for more than $96 \%$ of the total $\mathrm{Cu}$ released from CuO NPs at $72 \mathrm{~h}$. This indicated that $\mathrm{Cu}$ released into soluble matrix mainly existed in the form of DHA- $\mathrm{Cu}^{2+}$ complexes. These results suggested that interactions between DHA molecules and $\mathrm{Cu}$ were the main driving force for enhanced particle dissolution, rather than the surface area of contact between particles and aqueous media. Moreover, the ability of DHA to form complexes with $\mathrm{Cu}$ and the extent of adsorption of DHA on CuO NPs were both observed to be reduced at higher levels of DHA ( $\left.>16.09 \mathrm{mg} \mathrm{C} \mathrm{L}^{-1}\right)$ after carbon standardization. Increased intermolecular forces promoted by the negative charge-assisted $\mathrm{H}$-bond may help explain why selfaggregation or homo-conjugation occurred among DHA molecules. Self-aggregation or homo-conjugation reduced the content of carboxyl and phenolic hydroxyl groups that are available for binding per unit of mass. This may also be the reason why the adsorption capacity was not saturated even at the highest level of DHA. Our findings assist in a better understanding of the mechanisms underlying the interactions between DHA and CuO NPs, and pointed out the important role of the dose of DOM on the environmental behavior of metal oxide NPs.

\section{Declaration of competing interest}

The authors declare no competing financial interest.

\section{Acknowledgment}

National Natural Science Foundation of China, China (41703111, 41967039, 41701571, 41703121).Talent cultivation project at Kunming University of Science and Technology, China (KKSY201622012). The framework of the "NANOFASE" project supported by the European Union's Horizon 2020 research and innovation programme, European Research Council (642007).

\section{Appendix A. Supplementary data}

Supplementary data to this article can be found online at https://doi.org/10.1016/j.chemosphere.2019.125612.

\section{References}

Aiken, G.R., Hsu-Kim, H., Ryan, J.N., 2011. Influence of dissolved organic matter on the environmental fate of metals, nanoparticles, and colloids. Environ. Sci. Technol. 45, 3196-3201.

Akaighe, N., MacCuspie, R.I., Navarro, D.A., Aga, D.S., Banerjee, S., Sohn, M. Sharma, V.K., 2011. Humic acid-induced silver nanoparticle formation under environmentally relevant conditions. Environ. Sci. Technol. 45, 3895-3901.

Baek, Y.-W., An, Y.-J., 2011. Microbial toxicity of metal oxide nanoparticles (CuO, NiO, $\mathrm{ZnO}$, and $\mathrm{Sb}_{2} \mathrm{O}_{3}$ ) to Escherichia coli, Bacillus subtilis, and Streptococcus aureus. Sci. Total Environ. 409, 1603-1608.

Benedetti, M.F., Milne, C.J., Kinniburgh, D.G., Riemsdijk, W.H.V., Koopal, L.K., 1995. Metal ion binding to humic substances: application of the non-ideal competitive adsorption model. Environ. Sci. Technol. 29, 446-457.

Berg, M., Stengel, C., Trang, P.T.K., Viet, P.H., Sampson, M.L., Leng, M., Samreth, S. Fredericks, D., 2007. Magnitude of arsenic pollution in the Mekong and red river deltas - Cambodia and vietnam. Sci. Total Environ. 372, 413-425.

Bian, S.W., Mudunkotuwa, I.A., Rupasinghe, T., Grassian, V.H., 2011. Aggregation and dissolution of $4 \mathrm{~nm} \mathrm{ZnO}$ nanoparticles in aqueous environments: influence of $\mathrm{pH}$, ionic strength, size, and adsorption of humic acid. Langmuir 27, 6059-6068.

Borm, P., Klaessig, F.C., Landry, T.D., Moudgil, B., Pauluhn, J., Thomas, K., Trottier, R. Wood, S., 2006. Research strategies for safety evaluation of nanomaterials, Part $\mathrm{V}$ : role of dissolution in biological fate and effects of nanoscale particles. Toxicol. Sci. 90, 23-32. 
Chen, W., Westerhoff, P., Leenheer, J.A., Booksh, K., 2015. Fluorescence excitationemission matrix regional integration to quantify spectra for dissolved organic matter. Environ. Sci. Technol. 37, 5701-5710.

Conway, J.R., Adeleye, A.S., Gardeatorresdey, J., Keller, A.A., 2015. Aggregation, dissolution, and transformation of copper nanoparticles in natural waters. Environ. Sci. Technol. 49, 2749-2756.

David, C.A., Galceran, J., Rey-Castro, C., Puy, J., Companys, E., Salvador, J., Monne, J., Wallace, R., Vakourov, A., 2012. Dissolution kinetics and solubility of ZnO nanoparticles followed by AGNES. J. Phys. Chem. C 116, 11758-11767.

Gao, X., Avellan, A., Laughton, S., Vaidya, R., Rodrigues, S.M., Casman, E.A., Lowry, G.V., 2018. CuO nanoparticle dissolution and toxicity to wheat (Triticum aestivum) in rhizosphere soil. Environ. Sci. Technol. 52, 2888-2897.

Ghosh, S.K., Pal, T., 2007. Interparticle coupling effect on the surface plasmon resonance of gold nanoparticles: from theory to applications. Chem. Rev. 107, 4797-4862.

Gilli, G., Gilli, P., 2000. Towards an unified hydrogen-bond theory. J. Mol. Struct. 552, $1-15$.

Gunsolus, I.L., Mousavi, M.P.S., Hussein, K., Buehlmann, P., Haynes, C.L., 2015. Effects of humic and fulvic acids on silver nanoparticle stability, dissolution, and toxicity. Environ. Sci. Technol. 49, 8078-8086.

Hernández, D., Plaza, C., Senesi, N., Polo, A., 2006. Detection of copper(II) and zinc(II) binding to humic acids from pig slurry and amended soils by fluorescence spectroscopy. Environ. Pollut. 143, 212-220.

Jayalath, S., Wu, H., Larsen, S.C., Grassian, V.H., 2018. Surface adsorption of suwannee river humic acid on $\mathrm{TiO}_{2}$ nanoparticles: a study of $\mathrm{pH}$ and particle size. Langmuir 34, 3136-3145.

Jekel, M.R., 1986. The stabilization of dispersed mineral particles by adsorption of humic substances. Water Res. 20, 1543-1554.

Jiang, C., Aiken, G.R., Hsu-Kim, H., 2015. Effects of natural organic matter properties on the dissolution kinetics of zinc oxide nanoparticles. Environ. Sci. Technol. 49, $11476-11484$.

Jiang, C., Castellon, B.T., Matson, C.W., Aiken, G.R., Hsukim, H., 2017. Relative contributions of copper oxide nanoparticles and dissolved copper to $\mathrm{Cu}$ uptake kinetics of gulf killifish (fundulus grandis) embryos. Environ. Sci. Technol. 51, 1395-1404.

Kang, S., Xing, B., 2005. Phenanthrene sorption to sequentially extracted soil humic acids and humins. Environ. Sci. Technol. 39, 134-140.

Khataee, A., Movafeghi, A., Mojaver, N., Vafaei, F., Tarrahi, R., Dadpour, M.R., 2016 Toxicity of copper oxide nanoparticles on spirodela polyrrhiza: assessing physiological parameters. Res. Chem. Intermed. 43, 1-15.

Leenheer, J.A., 1994. Chemistry of dissolved organic-matter in rivers, lakes, and reservoirs. In: Baker, L.A. (Ed.), Advanced in Chemistry Series. Environmental Chemistry of Lakes and Reservoirs, pp. 195-221.

Leenheer, J.A., Croue, J.P., 2003. Characterizing aquatic dissolved organic matter Environ. Sci. Technol. 37, 18A-26A.

Liang, L., Luo, L., Zhang, S., 2011. Adsorption and desorption of humic and fulvic acids on $\mathrm{SiO}_{2}$ particles at nano- and micro-scales. Colloids Surf., A 384, 126-130.

Liu, A., Gonzalez, R.D., 2000. Modeling adsorption of copper(II), cadmium(II) and lead(II) on purified humic acid. Langmuir 16, 3902-3909.

Ma, H., Allen, H.E., Yin, Y., 2001. Characterization of isolated fractions of dissolved organic matter from natural waters and a wastewater effluent. Water Res. 35 985-996.

Mahmudov, K.T., Kopylovich, M.N., Guedes da Silva, M.F.C., Pombeiro, A.J.L., 2017 Non-covalent interactions in the synthesis of coordination compounds: recent advances. Coord. Chem. Rev. 345, 54-72.

Milne, C.J., Lapworth, D.J., Gooddy, D.C., Elgy, C.N., Valsami-Jones, E., 2017. Role of humic acid in the stability of Ag nanoparticles in suboxic conditions. Environ. Sci. Technol. 51, 6063-6070.

Mostofa, K.M.G., Liu, C.-q., Mottaleb, M.A., Wan, G., Ogawa, H., Vione, D., Yoshioka, T., Wu, F., 2013. Dissolved organic matter in natural waters. In: Mostofa, K.M.G., Yoshioka, T., Mottaleb, A., Vione, D. (Eds.), Photobiogeochemistry of Organic Matter: Principles and Practices in Water Environments. Springer Berlin Heidelberg, Berlin, Heidelberg, pp. 1-137.

Mudunkotuwa, I.A., Grassian, V.H., 2010. Citric acid adsorption on $\mathrm{TiO}_{2}$ nanoparticles in aqueous suspensions at acidic and circumneutral $\mathrm{pH}$ : surface coverage, surface speciation, and its impact on nanoparticle-nanoparticle interactions. J. Am. Chem. Soc. 132, 14986-14994.

Nierop, K.G. Jansen, B., Vrugt, J.A., Verstraten, J.M., 2002. Copper complexation by dissolved organic matter and uncertainty assessment of their stability constants. Chemosphere 49, 1191-1200.

Pan, B., Ghosh, S., Xing, B., 2008. Dissolved organic matter conformation and its interaction with pyrene as affected by water chemistry and concentration. Environ. Sci. Technol. 42, 1594-1599.

Pan, B., Wang, P., Wu, M., Li, J., Zhang, D., Xiao, D., 2012. Sorption kinetics of ofloxacin in soils and mineral particles. Environ. Pollut. 171, 185-190.

Pan, B., Zhang, D., Li, H., Wu, M., Wang, Z., Xing, B., 2013. Increased adsorption of sulfamethoxazole on suspended carbon nanotubes by dissolved humic acid. Environ. Sci. Technol. 47, 7722-7728.

Park, J., Kim, S., Yoo, J., Lee, J.S., Park, J.W., Jung, J., 2014. Effect of salinity on acute copper and zinc toxicity to tigriopus japonicus: the difference between metal ions and nanoparticles. Mar. Pollut. Bull. 85, 526-531.

Peng, C., Shen, C., Zheng, S., Yang, W., Hu, H., Liu, J., Shi, J., 2017. Transformation of $\mathrm{CuO}$ nanoparticles in the aquatic environment: influence of $\mathrm{pH}$, electrolytes and natural organic matter. Nanomaterials 7.

Philippe, A., Schaumann, G.E., 2014. Interactions of dissolved organic matter with natural and engineered inorganic colloids: a review. Environ. Sci. Technol. 48, 8946-8962.

Plaza, C., Brunetti, G., Senesi, N., Polo, A., 2006. Molecular and quantitative analysis of metal ion binding to humic acids from sewage sludge and sludge-amended soils by fluorescence spectroscopy. Environ. Sci. Technol. 40, 917-923.

Sánchezmarín, P., Santosecheandía, J., Nietocid, M., ÁlvarezSalgado, X.A., Beiras, R., 2010. Effect of dissolved organic matter (DOM) of contrasting origins on $\mathrm{Cu}$ and $\mathrm{Pb}$ speciation and toxicity to Paracentrotus lividus larvae. Aquat. Toxicol. 96, 90-102.

Vijver, M.G., Zhai, Y., Wang, Z., Peijnenburg, W.J.G.M., 2018. Emerging investigator series: the dynamics of particle size distributions need to be accounted for in bioavailability modelling of nanoparticles. Environ. Sci. Nano. 5, 2473-2481.

Wang, L.F., Habibul, N., He, D.Q., Li, W.W., Zhang, X., Jiang, H., Yu, H.Q., 2015. Copper release from copper nanoparticles in the presence of natural organic matter. Water Res. 68, 12-23.

Wang, Z., Zhang, L., Zhao, J., Xing, B., 2016. Environmental processes and toxicity of metallic nanoparticles in aquatic systems as affected by natural organic matter. Environ. Sci. Nano. 3, 240-255.

Weichenthal, S., Dufresne, A., Infante-Rivard, C., 2007. Indoor ultrafine particles and childhood asthma: exploring a potential public health concern. Indoor Air 17, 81-91.

Yamashita, Y., Jaffé, R., 2008. Characterizing the interactions between trace metals and dissolved organic matter using excitation-emission matrix and parallel factor analysis. Environ. Sci. Technol. 42, 7374-7379.

Yang, K., Lin, D.H., Xing, B.S., 2009. Interactions of humic acid with nanosized inorganic oxides. Langmuir 25, 3571-3576.

Zafar, S., Akhtar, S., Tariq, T., Mushtaq, N., Akram, A., Ahmed, A., Arif, M., Naeem, S., Anwar, S., 2014. Determination of pKa values of new phenacyl-piperidine derivatives by potentiometric titration method in aqueous medium at room temperature $\left(25 \pm 0.5^{\circ} \mathrm{C}\right)$. Pak. J. Pharm. Sci. 27, 925-929.

Zhao, J., Cao, X., Liu, X., Wang, Z., Zhang, C., White, J.C., Xing, B., 2016. Interactions of CuO nanoparticles with the algae Chlorella pyrenoidosa: adhesion, uptake, and toxicity. Nanotoxicology 10, 1297-1305.

Zhao, J., Chu, G., Pan, B., Zhou, Y., Wu, M., Liu, Y., Duan, W., Lang, D., Zhao, Q., Xing, B., 2018. Homo-conjugation of low molecular weight organic acids competes with their complexation with Cu(II). Environ. Sci. Technol. 52, 5173-5181.

Zhao, J., Liu, Y., Pan, B., Gao, G., Liu, Y., Liu, S., Liang, N., Zhou, D., Vijver, M.G., Wjgm, P., 2017. Tannic acid promotes ion release of copper oxide nanoparticles: impacts from solution pH change and complexation reactions. Water Res. 127, 59-67.

Zhao, J., Wang, Z., Dai, Y., Xing, B., 2013. Mitigation of CuO nanoparticle-induced bacterial membrane damage by dissolved organic matter. Water Res. 47, 4169-4178.

Zook, J.M., Halter, M.D., Cleveland, D., Long, S.E., 2012. Disentangling the effects of polymer coatings on silver nanoparticle agglomeration, dissolution, and toxicity to determine mechanisms of nanotoxicity. J. Nanoparticle Res. 14, 1-9. 